\title{
Labor Opportunism of the Personnel of Medical Institution
}

\author{
Bodrov 0. G. \\ Kazan Federal University, Institute of Management, Economics and Finance, Kazan, 420008, Russia
}

\section{Doi:10.5901/mjss.2015.v6n1s3p277}

\begin{abstract}
Methods of identification and quantitative assessment of level of labor opportunism of the personnel on the basis of the analysis of labor opportunism of the personnel of a clinical oncologic dispensary, forms of its manifestation in the organization in view of various hierarchical levels of official categories of workers are analyzed in this article. The special attention is paid to research of the reasons of emergence of labor opportunism of employees.
\end{abstract}

Keywords: labor opportunism, regression model, opportunistic trap, stability of opportunistic balance.

\section{Introduction}

The opportunistic behavior is defined by 0 . Williamson, as "prosecution of own interest, on insidiousness use" (Williamson, 1993). It implies violations of the assumed obligations, in the course of interactions of firms where often there are cases of violation of contractual obligations.

We consider labor opportunism as the deliberate hidden worker's violation of the assumed liabilities provided by the labor contract.

In economic literature there are descriptions of various forms of opportunistic behavior: adverse selection, "extortion", "moral risk", negligence - as consciously allowed negligence, their various versions and combinations. However for the majority of them the general conditions of emergence when collecting reliable information about behavior of worker demands big expenses are characteristic or is impossible in general, and "only small part of what people actually do at work can be controlled in details" (Nelson, 1981). The most widespread kind of opportunistic behavior of staff of medical institutions - "shirking" when the worker carries out the duties with smaller return, than it is required under the contract, or some duties carries out not in full, for example, when the doctor only superficially fills in clinical records, or execution of any duties shifts to nurses. To reveal this type of shirking is very difficult and expensive. Shirking leads to decline in quality of the performed work.

Labor opportunism is a source of the "behavioral" uncertainty causing considerable problems in the form of obvious and hidden losses. By E.V. Popov's estimates ( Popov and Simonova, 2005), shrinking leads to decrease in productivity of activity on average by $34 \%$, negligence leads to growth of expenses on average by $27,5 \%$. Besides, the opportunism generates huge costs for protection against this type of behavior.

The labor opportunism extends promptly on the organizations, successfully "infecting" them with quickness of computer viruses. However unlike IT technologies organization haven't developed reliable protection programs from opportunism "viruses" yet. Often it is connected rather with the low level of study of its Russian specifics, environment and the reasons of emergence than with weak diagnostics and "blurring" of criteria of identification of forms of manifestation of labor opportunism (Bodrov, 2013, 2014). The problem is complicated by lack of techniques of assessment not only losses of the organizations from prosperity of sophisticated opportunistic practices of working collectives but also lack of any of acceptable methods of measurement of developed opportunism level in organization.

Most of researchers (Bose A. et al., 2010, Vafai K., 2010, 2002, Bevia and Corchon, 2006), etc. Consider imperfection of formal rules and contracts which, in their opinion, distort incentives of workers as the main reasons for labor opportunism of the personnel of the organization. So, for example, Bose A. (2010) considering the reasons of emergence of sabotage of workers in relation to the colleagues, came to a disputable conclusion that this problem can be overcome by means of change of the principles of compensation. He claims that the source of sabotage roots in envy of employees when one is more successful and productive, than the other. Respectively this distinction defines a difference in compensation therefore the incentive to sabotage disappears if wages are equalized for workers with different abilities and various contributions to result of teamwork.

In our opinion, this offer will lead only to sabotage strengthening, but not in relation to the colleagues any more, but 
in relation to the management. Equalization in payment provides disappearance of incentive of increase in labor costs, and workers will seek to minimize them in every possible way, defining that limit to which it is possible to bungle without serious consequences, without causing complaints from the management.

Vafai K. (2010), considering methods of overcoming of individual opportunism of the head in the form of abuse of opportunities and abuse of power, and also in two types of group opportunism, namely arrangement to the agent and arrangement to the owner, suggests to derive the optimal contract which would protect the organizations from these types of opportunism.

A number of the conducted empirical researches show that the aspiration of heads of firms to receive information on the subordinates causes emergence of various forms of abuse of power. Thus the personnel of firms isn't able to take effective legal formal measures against these forms of manifestation of opportunism of the heads (e.g., Klitgaard, 1988; Peirce, Smolinski and Rosen, 1998; Timmerman and Bajema, 1999; Vardi and Weitz, 2004; Campos and Pradhan, 2007.

On our deep belief the nature of labor opportunism, especially in the Russian organizations, has informal character, it acts as "counterbalance" to existing formal legitimately accepted rules, supplementing their defects, outdated provisions and, created on this basis, inefficient communicative processes. The opportunism of personnel and heads of the organizations is directed on restoration of the broken balance between their mutual expectations. The labor opportunism of the personnel is response on manager's opportunism which is in abundance at the majority of the organizations.

\section{Methods}

\subsection{Research model}

For research of level of labor opportunism in an oncological clinic the questioning method was used. Two types of questionnaires were made: the first questionnaire - for an assessment of opportunism of staff of the organization (nurses and doctors), and the second - for heads of the organization (the chief physician, his deputies, chiefs of departments).

During research, on the basis of analysis of these questionnaires, there were constructed regression models which allowed defining the most significant factors conducting to labor opportunism of the personnel.

Using the received regression equations, the level of opportunism of employees and heads of hospital was calculated and stability degree of "opportunistic traps" was estimated.

\subsection{Group of research}

In this research continuous selection was used. The personnel of a clinical oncological dispensary participated in poll included 172 doctors and 442 nurses of all divisions and branches aged from 22 till 65 years, and also 42 heads of various levels of management, in all 656 people.

\subsection{Instruments of data collection}

Questionnaires include 31 questions which express various factors of emergence and manifestation of labor opportunism in the organization. Factors were revealed during interviewing of the group of experts which included representatives of various offices and categories of the medical personnel of oncology dispensary: the deputy chief physicians managing offices, doctors, nurses. Results of questionnaires were processed with use of a method of the smallest squares of the regression analysis (OLS).

In the analysis of questionnaires the conventional verbal and numerical scale of Harrington which is widely and effectively used in practice at the solution of various tasks by expert methods was applied for a quantitative assessment of the received results (Glotov and Pavelyev, 1984).

\subsection{Analysis of data}

Results of questioning of 618 medical employees of hospital and 42 heads of various levels were analyzed by means of a package of the applied Gretl programs. According to a research objective, necessary statistical calculations were carried out with use of correlation, the analysis of deviations, t-test and methods of the regression analysis. 


\section{Result}

The regression analysis of the factors influencing opportunism of the personnel showed that it appeared the most significant of them - opportunism of the managers of hospital ( $\mathrm{X}_{22} \_$, model 2, tab. 1).

Table 1. Factors of opportunism of workers

Model2:OLS, used supervision 1-618 Dependent variable: $\mathrm{X} 23$ opportunism of workers

\begin{tabular}{ccccc}
\hline Variables & $\mathbf{B}$ & Std. Error & $\mathbf{t}$ & $\mathbf{p}$ \\
\hline $\mathrm{X}_{1}$ & .09 & .03 & 2.82 & .01 \\
$\mathrm{X}_{4}$ & .09 & .04 & 2.41 & .02 \\
$\mathrm{X}_{5}$ & .01 & .05 & 2.66 & .01 \\
$\mathrm{X}_{11 \_1}$ & -.13 & .05 & -2.57 & .01 \\
$\mathrm{X}_{12 \_} \mathrm{X}_{14}$ & .25 & .05 & 5.08 & .00 \\
$\mathrm{X}_{22 \_1}$ & -.07 & .03 & -2.74 & .01 \\
\multicolumn{5}{c}{} \\
\hline
\end{tabular}

The revealed factors were ranged on extent of their influence on the level of opportunism of employees of hospital (tab. 2).

Table 2. Rank of the factors influencing opportunism of workers

\begin{tabular}{|c|l|c|}
\hline Variables & Name of a factor & B \\
\hline$X_{22 \_1}$ & Level of opportunism of the managers of hospital & .33 \\
\hline$X_{12 \_}$ & Level of trust of the office managers to workers & .25 \\
\hline$X_{11 \_1}$ & Trust level to the managers of hospital & .13 \\
\hline$X_{1}$ & Workload degree & .09 \\
\hline$X_{4}$ & Workload degree (managers tasks) which do not belong to administrative duty & .08 \\
\hline$X_{14}$ & $\begin{array}{l}\text { Dependence of the size of compensation of the worker on results of his efforts (the more } \\
\text { he works - the more he gets paid) }\end{array}$ & -.07 \\
\hline$X_{5}$ & Degree of satisfaction with work & .01 \\
\hline
\end{tabular}

Factor $X_{22}{ }_{1}$ - opportunism of the managers of hospital has the greatest impact on opportunism of workers of an oncological clinic $\left[\mathrm{R}=.57, \mathrm{R}^{2}=.33, \mathrm{~F}=8.62, \mathrm{p}<.01\right]$. The opportunism of workers is reciprocal protective reaction to managers opportunism.

On the basis of the conducted research on data of model 2 (tab. 1) the equation of regression of opportunism of the personnel was constructed that allowed to calculate its quantitative level:

$\mathrm{Y}=.09 \mathrm{X} 1+.08 \mathrm{X} 4+.01233 \mathrm{X} 5-.01 \mathrm{X} 11 \_1+.02 \mathrm{X} 12 \_2-.07 \mathrm{X} 14+.331474 \mathrm{X} 22 \_1=.28[1]$

The obtained settlement data which range of changes is in the range from 0 to 1 , testify to rather low level of opportunism of the personnel - the calculated value made. 28 .

It is characteristic that growth of trust of managers of offices to the workers $\left(X_{12} 2\right.$, tab. 2) leads to growth of labor opportunism of the personnel which abuses trust $\left[R=.50, R^{2}=.25, F=5.08, p<.05\right]$. Thus growth of level of trust to the managers of hospital from the personnel $\left(X 11 \_1\right.$, tab. 2) has the return impact on its labor opportunism, reducing it $[R=-$ $\left..36, \mathrm{R}^{2}=.13, \mathrm{~F}=-2.57, \mathrm{p} \& \mathrm{lt} ; .05\right]$.

The opportunism of workers of an oncological clinic increases because of negative dependence of the size of compensation of the worker on results of his efforts (the more he works - the more he gets paid) $\left(X_{14}\right.$, tab. 2 more) $[R=-$ $\left..26, R^{2}=.07, p<.05\right]$. The increase in the size of labor costs of the personnel doesn't lead to growth of compensation. Average value of answers to the matter of the questionnaire made 64 on Harrington's scale, it means that compensation of the medical personnel on average only for $64 \%$ is attached to work expenses.

The analysis of the forms of manifestation of opportunism of the managers influencing opportunism of workers is provided in regression model 3 which results are presented in table 3. 
Table 3. Regression analysis of forms of opportunism of the managers

Model 3:OLS, used supervision 1-618

Dependent variable: $\mathrm{X}_{23}$ - managers opportunism

\begin{tabular}{ccccc}
\hline Variables & $\mathbf{B}$ & Std. Error & $\mathbf{t}$ & $\mathbf{p}$ \\
\hline $\mathrm{X}_{3}$ & .07 & .03 & 2.28 & .02 \\
$\mathrm{X}_{4}$ & .23 & .04 & 5.30 & $<.01$ \\
$\mathrm{X}_{6 \_1}$ & .15 & .04 & 4.12 & $<.04$ \\
$\mathrm{X}_{7}$ & .13 & .03 & 3.87 & .00 \\
$\mathrm{X}_{8 \_}$ & .16 & .04 & 4.07 & .00 \\
\hline \multicolumn{5}{c}{} \\
\hline
\end{tabular}

Results of an assessment of extent of influence of the revealed managers opportunism forms on opportunism of the personnel are presented in table 4.

Table 4. Extent of influence of forms of opportunism of the managers on opportunism of workers

\begin{tabular}{clc}
\hline Variables & Name of a factor & $B$ \\
\hline$X_{4}$ & Workload degree (managers tasks) which do not belong to functions & .23 \\
$X_{8 \_} 2$ & Unfair attitude of the managers of office towards subordinates & .16 \\
$X_{6} 1$ & Regular violations or procrastination of execution of the promises made by the hospital managers. & .15 \\
$X_{7}$ & Extent of control from the manager of office of process and results of the performed works (the regularity of \\
$X_{3}$ & rounds, filling of clinical records, controls terms of performance of instructions, check of the course of & .13 \\
& performance of long tasks, etc.) & .07 \\
& Requirements to perform the work which doesn't correspond to functions
\end{tabular}

Apparently according to tables 3 and 4 , in a greater degree opportunism of the managers is shown in regular loading of subordinates by the work (tasks) which doesn't belong to their functions. $\left[R=.48, R^{2}=.23, p<.01\right]$. This factor causes the maximum irritation of employees.

For identification of the reasons of opportunism of the managers regression model 5 (tab. 5 ) was constructed where as a dependent variable the indicator $\left(\mathrm{X}_{22}{ }_{2}\right)$ - "The level of opportunism of the managers of hospital" was applied.

Table 5. Regression analysis of opportunism of the hospital managers

Model 5:OLS, supervision used 1-618

Dependent variable: $X_{22}{ }_{1}-$ opportunism of the managers of hospital

\begin{tabular}{|c|c|c|c|c|}
\hline Variables & B & Std. Error & $t$ & $p$ \\
\hline$x_{2}$ & .05 & .02 & 2.59 & .01 \\
\hline$X_{4}$ & .07 & .03 & 2.74 & .01 \\
\hline$X_{5}$ & -.06 & .03 & -2.02 & .04 \\
\hline$X_{7}$ & -.06 & .02 & -2.54 & .01 \\
\hline$X_{8 \_1}$ & .12 & .04 & 3.03 & .00 \\
\hline$X_{8}^{-} 2$ & -.14 & .04 & -3.38 & .00 \\
\hline$X_{9 \_1}^{-1}$ & .17 & .04 & 4.26 & .00 \\
\hline$X_{9} 2$ & -.15 & .04 & -3.78 & .00 \\
\hline$X_{11 \_1}$ & .25 & .04 & 5.86 & .00 \\
\hline $\mathrm{X}_{11 \_2}$ & -.15 & .04 & -3.30 & .00 \\
\hline $\mathrm{X}_{21 \_1}$ & .06 & .01 & 3.56 & .00 \\
\hline$X_{22 \_}$ & .68 & .02 & 24.52 & .00 \\
\hline$X_{23}$ & .11 & .03 & 3.92 & .00 \\
\hline$X_{30}$ & .05 & .02 & 2.52 & .01 \\
\hline
\end{tabular}

In the table 6 the factors revealed in model 5 are ranged according to extent of influence on opportunism of the hospital managers. 
Table 6. Rank of factors of opportunism of the hospital managers.

\begin{tabular}{|c|l|c|}
\hline Variables & Name of the factor & $B$ \\
\hline$X_{22 \_}$ & Level of opportunism of managers of offices & .68 \\
\hline$X_{11 \_1}$ & Level of your trust to the hospital managers. & .25 \\
\hline$X_{9 \_} 1$ & Shifting their work to subordinates by the hospital managers. & .17 \\
\hline$X_{9} \_$ & Shifting of their work to subordinates by the managers of office. & -.15 \\
\hline$X_{11 \_}$ & Level of your trust to the managers of office & -.15 \\
\hline$X_{8} \_$ & Cases of the unfair attitude of the managers of office towards subordinates & -.14 \\
\hline$X_{8} 1$ & Cases of the unfair attitude of the managers of hospital towards subordinates & .12 \\
\hline$X_{23}$ & Level of opportunism of workers & .11 \\
\hline$X_{4}$ & Workload degree (managers tasks) which doesn't belong to functions & .07 \\
\hline$X_{5}$ & Degree of satisfaction with work & -.06 \\
\hline$X_{7}$ & Amount of control of process and results of the performed works on the part of the manager of office & -.06 \\
\hline$X_{21} 1$ & Efficiency and rationality of actions of the hospital managers. & .05 \\
\hline$X_{2}$ & Do you know the indicators of productivity of your work? & .05 \\
\hline$X_{30}$ & Age category & .05 \\
\hline
\end{tabular}

Apparently according to the data of tab. 6 , the opportunism of managers of offices (factor $\mathrm{X}_{22}{ }_{2}$ ) has the maximum impact on the level of opportunism of the managers of hospital $\left[R=.82, R^{2}=.68, p<.01\right]$. It means that the opportunism of the managers of hospital for $68,3 \%$ depends on opportunism of managers of offices. Influence of opportunism of the personnel is very insignificant $\left(\mathrm{X}_{23}\right.$ factor) $\left[\mathrm{R}=.33, \mathrm{R}^{2}=.11, \mathrm{p}<.01\right]$.

These conclusions correspond to the received results of the analysis of labor opportunism of the personnel (see model 2, tab. 3) where the greatest extent of influence on opportunism of the personnel is rendered by opportunism of the managers of hospital $\left(R^{2}=.33\right)$.

The conducted research on data of model 5 (tab. 5) allowed to construct the equation of regression of opportunism of the managers of a clinic and to calculate its quantitative level:

$Y=.05 X 2+.07 X 4-.07 X 5-.06 X 7+.12 X 8 \_1-.13 X 8 \_2+.17 X 9 \_1-15$ X9_2 +.25X11_1-15X11_2 +.06X21_1 $+.68 \times 22 \_2+.11 \times 23+.05 \times 30=.40[2]$

Predicted level of opportunism of the managers of a clinic made .40 that significantly exceeds the level of opportunism of the personnel which made 28 .

\section{Discussion}

The received results of the conducted research allow to claim that a source of labor opportunism in a clinic is interdependence of opportunism of the management of hospital and managers of offices. Nature of this interaction generates the corresponding wave effects by which the level of opportunism of all personnel of a clinic is defined. For check of reliability of this conclusion models 6 and 7 of pair regressions were constructed at which on the received coefficients of regression it is possible to estimate force of mutual influence of these factors.

Table 6. Influence of opportunism of managers of offices on opportunism of heads of hospital

Model 6: OLS, supervision used 1-618

Dependent variable: $\mathrm{X}_{22}{ }_{1}$-opportunism heads of hospital

\begin{tabular}{clccc}
\hline Variables & $\mathbf{B}$ & Std. Error & $\mathbf{t}$ & $\mathrm{p}$ \\
\hline $\mathrm{X}_{22 \_} 2$ & .94 & .01 & 70.11 & .00 \\
\hline \multicolumn{5}{c}{$\mathbf{R}=.94 \mathrm{R}^{2}=.89 \mathrm{~F}=\mathbf{4 9 1 6 . 5 5 \mathrm { p } < . 0 1}$} \\
\hline
\end{tabular}

A dependent variable was $\mathrm{X}_{22 \_1}$ - opportunism of heads of the hospital and independent - $\mathrm{X}_{22}{ }_{2}$-opportunism managers of offices.

This model 6 reflects close dependence: change of level of opportunism of managers of offices on 1 will lead to change of level opportunism of heads of hospital on.94. In model 7 these variables were swapped: 
Table 7. Influence of opportunism of heads of hospital on opportunism of managers of offices

Model 7: OLS, supervision used 1-618

Dependent variable: $\mathrm{X}_{22}{ }_{2}$-opportunism managers of offices

\begin{tabular}{ccccc}
\hline Variables & B & Std. Error & $t$ & $\mathrm{p}$ \\
\hline $\mathrm{X}_{22 \_1}$ & .94 & .01 & 70.1181 & .00 \\
\hline \multicolumn{5}{c}{$\mathrm{R}=.94 \mathrm{R}^{2}=.89 \mathrm{~F}=\mathbf{4 9 1 6 . 5 5 \mathrm { p } < . 0 1}$} \\
\hline
\end{tabular}

Model 7 reflects dependence, equivalent on influence force: with a growth of level of opportunism of heads of hospital on 1 - level the opportunism of managers of offices will grow on.94.

The equilibrium constructive relations between key official categories are a condition of effective self-development of an oncological clinic. Balance in the labor relations form the comfortable moral and psychological labor atmosphere which doesn't constrain a creative initiative of the personnel, and itself is a powerful system motivator of labor activity.

For verification of this assumption the assessment of level of stability of the opportunistic balance which developed between heads of hospital and managers of offices was carried out.

In the formalized look the condition of stability of opportunistic balance can be presented in the form of the following dependence:

$$
\frac{\mathrm{OpH}}{\mathrm{OpM}}=1 \rightarrow \min \text { [3] }
$$

Where $\mathrm{OpH}$ - level of opportunism of heads of a clinic

OpM - level of opportunism of managers of offices.

Both parties are interested in minimization of level of opportunism as both suffer from the fact of its existence therefore this dependence is directed to a minimum. However, the equality condition in levels of opportunism can be met and at rather high values.

Level of opportunism of managers of offices was determined by results of the corresponding correlation and regression analysis. On the received coefficients of regression the regression equation is constructed [4]:

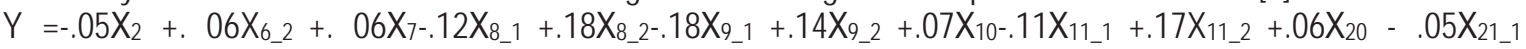
$+.08 \mathrm{X}_{21 \_2}+.71 \mathrm{X}_{22 \_1}+.05 \mathrm{X}_{23}=.39[4]$

Having substituted average values of the corresponding variables in this equation, the average quantitative assessment of level of opportunism of managers of offices of a clinic was calculated: $Y=.39$

Similar calculation of level of opportunism of heads of a clinic was carried out above on model 5 (tab. 5) and made .40 (the equation of regression [2]).

Stability of opportunistic balance in a clinic is almost ideal as it is most approached to 1:

$$
\frac{\mathrm{OpH}}{\mathrm{OpM}}=\frac{.40}{.39}=1.01
$$

This result is very close to the equilibrium.

\section{Conclusion}

Excess of level of opportunism of one of the parties causes aspiration of other party to restore the broken balance, having lifted own opportunism to an appropriate level. As it, as a rule, occurs in rather short-term period of time, the first party perceives strengthening of opportunism of the opponents as a direct call and starts increasing in reply in even bigger measure the level of opportunism. Then again opponents join this process that leads to emergence of a peculiar effect of competition which has destructive character. As a rule, it brings the organization into a condition of an opportunistic trap.

Anything similar isn't present in an oncological clinic where the long-term stable condition of opportunistic balance at rather low level was created. In this equilibrium situation there is no incentive to change or violation of the reached opportunistic balance unilaterally as the result of similar violation will be worse, than the developed equilibrium compliance.

The level of opportunism of the personnel is influenced by opportunism of the managers of a clinic (regression model 2 (tab. 3)). Thus the numerical value of opportunism of the personnel calculated on the equation of regression of model 2 makes.28 that is much lower than opportunism of the managers of a clinic (.40).

Stability of opportunistic balance of interaction of opportunism of the personnel and the managers makes 1.4

$$
\frac{O p M}{O p P}=\frac{.40}{.28}=1.40
$$


It means that the opportunism of the personnel isn't primary, its role is supporting, subordinated and is response to manager's opportunism. Considering that the tendency of interaction of opportunism of the parties, according to a formula [3], strives for equilibrium compliance, the tendency to growth of level of opportunism of the personnel in the short term to reach managers opportunism level is quite probable.

\section{References}

Bodrov, O., 2014, Main causes of Staff labor opportunism in organizations. Life Science Journal 2014; 11(9s), pp.400-408.

Safiullina, A.M., Odintsova, J.L., Zhilina, N.N.,Shamsutdinova, M.R. The main participants of innovation climate development (on the example of the Russian federation). Mediterranean Journal of Social Sciences, 5 (18 SPEC. ISSUE), pp. 197-202

Bose, A., D. Pal and D.E.M. Sappington, 2010. Equal Pay for Unequal Work: Limiting Sabotage in Teams. Journal of Economics and Management Strategy, 19, 25-53.

Bosman, R., Van Winden, F., 2002. Emotional hazard in a power-to-take experiment. Economic Journal, 112 (476),

pp. 147-169.

Campos, E. and S. Pradhan, 2007. The Many Faces of Corruption. Washington, D.C., The World Bank.

Glotov, V.A., Pavel'ev, V.V., 1984. Vector stratification. -M: Nauka, 132 p.

Klitgaard, R., 1988, Controlling Corruption, Berkeley: University of California Press.

Nelson, R.R., 1981. Research of productivity Growth and Productivity Differences: Dead Ends and New Departures// Journal of Economic Literature, 19(3), pp. 1029-1064.

Peirce, E., C. Smolinski and B. Rosen, 1998. Why Sexual Harassment Complaints Fall on Deaf Ears. Academy of Management Executive, 12, pp.41-54.

Popov E., Simonova V., 2005. Endogenous opportunism in the theory of a "principal-agent". Issues of economy, Vol. 3. pp. 118 - 130.

Safiullin, N.Z., Gafurov, I.R.,Safiullin, L.N., Odintsova, J.L. Education system of the world: Modern trends. Mediterranean Journal of Social Sciences, 5 (18 SPEC. ISSUE), pp. 91-94.

Timmerman, G. and C. Bajema, 1999. Sexual Harassment in Northwest Europe. European Journal of Women's Studies, 6, pp.419-439.

Vafai, Kouroche, 2010. Opportunism in Organizations. The Journal of Law, Economics, \& Organization, Vol. 26, No. 1(2010), pp. 158181.

Vafai, Kouroche, 2002. Preventing Abuse of Authority in Hierarchies. 20 International Journal of Industrial Organization 1143-66. 